\title{
EFEKTIFITAS KOMPRES HANGAT TERHADAP PENURUNAN NYERI DISMENOREA DENGAN SKALA BOURBANIS PADA REMAJA PUTRI DI SMPN 1 KARTOHARJO MAGETAN
}

\author{
Astin Nur Hanifah ${ }^{1}$, Syahda Febby Kuswantri ${ }^{2}$ \\ ${ }^{1,2}$ Jurusan Kebidanan Poltekkes Kemenkes Surabaya
}

\begin{abstract}
Abstrak
Dismenorea terbagi menjadi dismenorea primer yaitu nyeri karena kontraksi miometrium akibat produksi prostaglandin tanpa kelainan pada pelvis, dismenorea sekunder dimana nyeri disertai kelainan pada pelvis. Prevalensi dismenorea di Indonesia sebesar 64,25\% yang terdiri dari 54,89\% dismenorea primer dan 9,36\% dismenorea sekunder. Dilaporkan 30-60\% remaja wanita yang mengalami dismenorea, sebanyak $7-15 \%$ tidak pergi ke sekolah. Berdasarkan hasil wawancara dan studi pendahuluan yang dilakukan oleh siswi di SMPN 1 Kartoharjo Magetan Tahun 2020 dan diambil secara acak, didapatkan hasil bahwa dari 104 siswi didapatkan 58 siswi mengalami dismenorea dan tidak mengikuti pelajaran dikelas.Penelitian ini merupakan yang bersifat eksperimen semu (Quasi Experiment). Rancangan penelitian ini adalah Penelitian ini menggunakan one group pretest-posttest. Besar sampel berdasarkan total populasi sejumlah 58 responden. .Variabel bebas adalah Kompres Hangat. Variabel Terikat adalah Nyeri Dismenorea. Pengumpulan data dengan menggunakan kuesioner. Analisis data menggunakan Uji Paired Sample T-Test. Pengukuran tingkat nyeri menggunakan skala Bourbanis. Dari hasil penelitian menunjukkan bahwa siswi sebelum diberikan kompres hangat didapatkan tingkat nyeri 4 dan 5 yang merupakan nyeri sedang setelah dilakukan intervensi mengalami penurunan menjadi 2 dan 3 (Nyeri ringan). Siswi dapat berperan aktif dalam membantu menanggulangi masalah nyeri haid utamanya pada remaja dengan melakukan kompres hangat, siswi bisa mengatasi pada saat nyeri haid dengan melakukan Kompres Hangat secara teratur pada saat Dismenorea.
\end{abstract}

Kata kunci : Kompres Hangat ; Nyeri Dismenorea

\section{THE EFFECTIVENESS OF WARM COMPRESS ON THE REDUCTION OF DISMENOREA PAIN IN ADOLESCENT PRINCESSES AT SMPN 1 KARTOHARJO MAGETAN}

\begin{abstract}
Dysmenorrhoea is divided into primary dysmenorrhoea, namely pain due to myometrial contraction due to prostaglandin production without abnormalities in the pelvis, secondary dysmenorrhoea where pain is accompanied by abnormalities in the pelvis. The prevalence of dysmenorrhoea in Indonesia is $64.25 \%$ consisting of $54.89 \%$ primary dysmenorrhea and $9.36 \%$ secondary dysmenorrhoea. It is reported that $30-60 \%$ of young women who experience dysmenorrhoea, as much as $7-15 \%$ do not go to school. Based on the results of interviews and preliminary studies conducted by students at SMPN 1 Kartoharjo Magetan in 2020 and taken randomly, it was found that out of 104 students, 58 students had dysmenorrhoea and did not attend class lessons. This research is a quasi-experimental (Quasi Experiment). The design of this study was a pre and postest design. The sample size is based on a total population of 58
\end{abstract}


respondents. The independent variable is the Relaxation Technique. The dependent variable is Dysmenorrhoea Pain. Data collection using a questionnaire. Data analysis used Paired Sample T-Test. The results showed that before being given the relaxation technique, the students had pain levels of 4 and 5 which were moderate pain after the intervention decreased to 2 and 3 (mild pain). Students can play an active role in helping to overcome the problem of menstrual pain, especially in adolescents by doing the Relaxation Technique, students can overcome menstrual pain by doing warm compresses regularly during dysmenorrhoea.

\section{Keywords: Warm Compresses ; Dysmenorrhoea Pain}

\section{Pendahuluan}

Prevalensi dismenorea di Indonesia sebesar 64,25\% yang terdiri dari 54,89\% dismenorea primer dan 9,36\% dismenorea sekunder. Dilaporkan 30-60\% remaja wanita yang mengalami dismenorea, sebanyak 7-15\% tidak pergi ke sekolah atau bekerja. Berdasarkan hasil wawancara terhadap guru dan studi pendahuluan yang dilakukan oleh siswi di SMPN 1 Kartoharjo Magetan Tahun 2020 dan diambil secara acak, didapatkan hasil bahwa dari 104 siswi didapatkan 58 siswi mengalami dismenore dan tidak mengikuti pelajaran dikelas. ${ }^{9}$

Dismenorea primerdisebabkan akibat pelepasan sel-sel telur (ovulasi) dari indung telur (ovarium) berhubungan dengan gangguan keseimbangan hormon ${ }^{2}$. Didukung hasil penelitian oleh Larasati \& Faridah (2016) di Lampung menyatakan bahwa peningkatan prostaglandin menyebabkan hipertonus dan vasokonstriksi miometrium, sehingga terjadi iskemia dan nyeri perut bagian bawah. ${ }^{9}$

Nyeri saat menstruasi menimbulkan ketidaknyamanan pada wanita yang mengakibatkan wanita tersebut tidak dapat melakukan aktifitas sehari-hari. Mahasiswi yang mengalami dismenorea saat menstruasi akan mengakibatkan penurunan konsentrasi belajar dan motivasi belajar bahkan izin pulang sekolah dikarenakan tidak tahan dengan dismenorea yang dirasakan. ${ }^{10}$

Upaya penanganan dismenorea dapat dilakukan dengan terapi farmakologis dan non farmakologis. Terapi farmakologis dengan menggunakan obat analgesik dan obat penghambat pengeluaran hormon prostaglandin. ${ }^{11}$ Salah satu metode non farmakologis yang dapat digunakan sewaktu-waktu saat muncul adalah dengan kompres hangat. Relaksasi merupakan teknik pengendoran atau pelepasan ketegangan, misalnya: bernafas dalam dan pelan. Selain dapat menurunkan intensitas nyeri, kompres hangat nafas dalam juga dapat meningkatkan ventilasi paru dan meningkatkan oksigen darah. ${ }^{12}$ Prinsip yang mendasari penurunan nyeri oleh kompres hangat nafas dalam terletak pada fisiologi sistem saraf otonom yang merupakan bagian dari sistem saraf perifer yang mempertahankan homeostatis lingkungan internal individu. Penggunaan kompres hangat diharapkan dapat meningkatkan relaksasi otot-otot dan mengurangi nyeri akibat spasme atau kekakuan serta memberikan rasa hangat lokal. Pada umumnya panas cukup berguna untuk pengobatan. Panas meredakan iskemia dengan menurunkan kontraksi dan meningkatkan sirkulasi. Kompres hangat dapat menyebabkan pelepasan endorfin tubuh sehingga memblok transmisi stimulasi nyeri ${ }^{2}$. 
Pada kesempatan ini peneliti tidak melakukan penelitian pada semua manajemen nyeri. Peneliti hanya membatasi pada manajemen nyeri non farmakologis yaitu kompres hangatterhadap nyeri dismenorea.

Berdasarkan uraian dalam latar belakang di atas, maka peneliti merumuskan masalah "Bagaimanakah perbedaan intensitas nyeri kompres hangat dan kompres hangat terhadap nyeri dismenorea ?'Tujuan PenelitianMenganalisis perbedaan intensitas nyeri kompres hangat terhadap nyeri dismenorea

\section{Metode}

Jenis penelitian ini merupakan penelitian eksperimen semu (Quasi Experiment. Menurut (Notoatmodjo, 2012) rancangan eksperimen semu tidak memiliki ciri-ciri rancangan eksperimen sebenarnya karena variabel yang seharusnya dikontrol tidak dapat dilakukan atau sulit dilakukan ${ }^{2}$. Tahapan. Etik penelitian diajukan pada komisi etik Poltekkes Kemenkes Surabaya. Penelitian ini menggunakan one group pretestposttest dengan cara memberikan pretest (pengamatan awal) sebelum diberikan intervensi, kemudian setelah diberikan intervesi dilakukan posttest (pengamatan akhir) $)^{7}$.

Populasi penelitian ini siswi SMPN 1 Kartoharjo Magetan Tahun 2020 bulan Maret-Mei 2020 yang mengalami dismenorea dengan besar populasi 58 orang. Pengukuran Nyeri dismenhoroe dilakukan sebelum dan sesudah dilakukan Kompres Hangat. Identifikasi nyeri dismenorea (checklist skala nyeri Bourbanis dengan skala nyeri $1,2,3,4,5,6,7,8,9,10)$. Data yang telah ditabulasi dianalisa secara deskriptif. Untuk menguji hipotesis penelitian dilakukan 2 uji statistik yaitu Uji Paired Sample T-Test dan Uji Independent Sample T-Test. Perbedaan antara skala nyeri sebelum dilakukan kompres hangat dengan sesudah dilakukan kompres hangat di uji dengan menggunakan Uji Paired Sample T-Test.

\section{Hasil dan Pembahasan}

Tabel 1. Perbedaan Tingkat Nyeri Haid Pada Remaja Putri di SMPN 1 Kartoharjo Magetan Sebelum dan Sesudah dilakukan kompres hangat Bulan Maret -April 2020

\begin{tabular}{lcccccc}
\hline & Mean & $\begin{array}{c}\text { Std. } \\
\text { Deviation }\end{array}$ & $\begin{array}{c}\text { Std. Error } \\
\text { Mean }\end{array}$ & T & Df & $\begin{array}{c}\text { Sig. }(-2 \\
\text { tailed })\end{array}$ \\
\hline $\begin{array}{l}\text { Kompres Hangat Pra } \\
\text { Intervensi- Kompres } \\
\text { Hangat }\end{array}$ & 2.379 & 1.208 & 224 & 10.611 & 28 & .000 \\
Intervensi & & & & & \\
\hline
\end{tabular}

Pada Tabel diatas Hasil menggunakan Uji Paired Sample T-Test mengenai sebelum dan sesudah dilakukan kompres hangat didapatkan hasil nilai signifikansi yaitu $0,000(<0,05)$, maka disimpulkan ada perbedaan bermakna antara sebelum dan sesudah dilakukan kompres hangat.

Berdasarkan data tersebut juga menunjukkan bahwa peneliti melihat perubahan tingkat nyeri tersebut terjadi tidak hanya karena Kompres Hangat saja, tetapi dapat 
dilihat juga pada saat waktu melakukannya dan juga cara melakukannya. Melakukan teknik relaksasi secara teratur dengan memperhatikan cara melakukannya dengan menggunakan botol air hangat diawali dengan mengisi air hangat dalam botol tersebut, kemudian kain diletakkan diantara botol dan area kulit yang akan dikompres. Suhu untuk mengompres hangat sekitar $37-40^{\circ} \mathrm{C}$. Tidak dianjurkan mengompres lebih dari 20 menit, kecuali jika atas anjuran dokter ${ }^{5}$. Hal ini sejalan dengan penelitian oleh Arfa Aningsih (2018) di yogyakarta yang menyatakan bahwa kompres hangat merupakan salah satu pengobatan alternatif untuk mengurangi nyeri pada saat haid muncul dengan selalu memperhatikan cara yang benar untuk melakukannya agar dapat mendapatkan hasil yang memuaskan yaitu nyeri haid berkurang atau dapat teratasi dan dapat juga memperlancar sirkulasi darah, mengurangi rasa sakit dan nyeri, memberi ketenangan, mengurangi kejang otot serta menurunkan kekakuan tulang sendi. ${ }^{1}$

\section{Kesimpulan}

Hasil Pengukuran Tingkat Nyeri haid sebelum dilakukan kompres hangat pada remaja putri SMPN 1 Kartoharjo mendapatkan skala nyeri dengan intensitas nyeri sedang dan untuk hasil pengukuran tingkat nyeri sesudah dilakukan kompres hangat pada remaja putri SMPN 1 Kartoharjo mengalami penurunan dan intensitas nyeri menjadi nyeri ringan.

Informasi yang diperoleh dari penelitian ini dapat diaplikasikan oleh guru khususnya guru piket UKS di SMPN 1 Kartoharjo sehingga siswi yang mengalami Dismenorea mendapatkan pelayanan khususnya mengenai kompres hangatSehingga dapat mengurangi nyeri Dismenorea yang dialami.

\section{Daftar Pustaka}

1. Arfa, Aningsih. 2018. Menurunkan Nyeri Dismenore dengan Relaksasi. Jurnal Keperawatan Vol VIII No 2 : 137-141. 2011

2. Devi. 2012: 21-22. Buku Ajar Psikologi Kebidanan. Unmuh Ponorogo Press.

3. Kemenkes RI. 2013. Riset Kesehatan Dasar Riskesdas 2018. Jakarta: Penelitian dan Pengembangan Kesehatan Kemenkes RI

4. Notoatmojo. S. 2012. Metode Penelitian Kesehatan. Jakarta: Rineka Cipta

5. Nugraha. 2017. Menurunkan Nyeri Dismenore dengan Kompres Hangat. Jurnal Keperawatan Vol VII No 2 : 137-141. 2012

6. Nurhidayati. 2013. Belajar dan Pembelajaran. Jakarta: Rineka Cipta

7. Riadi. 2013. Metode Penelitian Kesehatan. Jakarta: Medika pustaka

8. Swarjana, I Ketut. 2012. Metodologi Penelitian Kesehatan. Yogyakarta: CV. Andi Offset.

9. Larasati TA, Alatas F. Dismenore primer dan faktor risiko dismenore primer pada remaja. Majority. 2016; 5(3): 79-84.

10. Suriani Beddu, Sitti Mukarramah,Viqy Lestahulu, 2013, Hubungan Status Gizi dan Usia Menarche dengan Dismenore Primer pada Remaja Putri.

11. Hartati, Walin, Esti. D. 2015. Pengaruh Teknik Relaksasi Effleurage Terhadap Nyeri Dismenore. Jurnal Keperawatan. 
12. Smeltzer, Suzanne C. dan Bare, Brenda G, 2002, Buku Ajar Keperawatan Medikal Bedah Brunner dan Suddarth (Ed.8, Vol. 1,2), Alih bahasa oleh Agung Waluyo (dkk), EGC, Jakarta. 